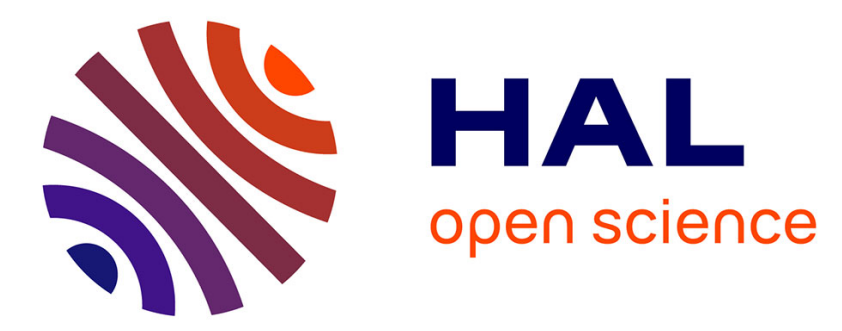

\title{
Nanofiltration of glucose and sodium lactate solutions: Variations of retention between single- and mixed-solute solutions
}

Antoine Bouchoux, Hélène Roux De-Balmann, Florence Lutin

\section{- To cite this version:}

Antoine Bouchoux, Hélène Roux De-Balmann, Florence Lutin. Nanofiltration of glucose and sodium lactate solutions: Variations of retention between single- and mixed-solute solutions. Journal of Membrane Science, 2005, 258 (1-2), pp.123-132. 10.1016/j.memsci.2005.03.002 . hal-01883123

\section{HAL Id: hal-01883123 \\ https://hal.science/hal-01883123}

Submitted on 27 Sep 2018

HAL is a multi-disciplinary open access archive for the deposit and dissemination of scientific research documents, whether they are published or not. The documents may come from teaching and research institutions in France or abroad, or from public or private research centers.
L'archive ouverte pluridisciplinaire HAL, est destinée au dépôt et à la diffusion de documents scientifiques de niveau recherche, publiés ou non, émanant des établissements d'enseignement et de recherche français ou étrangers, des laboratoires publics ou privés. 


\title{
NANOFILTRATION OF GLUCOSE AND SODIUM LACTATE \\ SOLUTIONS. VARIATIONS OF RETENTION BETWEEN SINGLE-
}

AND MIXED-SOLUTE SOLUTIONS.

\author{
Antoine Bouchoux ${ }^{* a}$, Hélène Roux-de Balmann ${ }^{a}$, Florence Lutin ${ }^{b}$ \\ a'Laboratoire de Génie Chimique, CNRS UMR 5503, \\ Université Paul Sabatier, 118 Route de Narbonne, \\ 31062 Toulouse Cedex 4, France \\ ${ }^{\mathrm{b}}$ Eurodia Industrie \\ 14-16 voie de Montavas \\ 91320 Wissous, France
}

\section{Abstract}

The aim of this work was to investigate NF as a purification step, i.e. sugar removal, in the production process of lactic acid from sodium lactate fermentation broth. Experiments were carried out with the Desal 5 DK membrane and solutions of increasing complexity, i.e. single-solute solution of sodium lactate and glucose and mixed-solute solutions containing both solutes. Concentrations close to those found in a fermentation broth were chosen. Experimental results were used to get the variations of the intrinsic retention versus the filtration flux in order to achieve comparisons without interference of concentration polarization. Quite distinct retentions were obtained for glucose and sodium lactate in singlesolute solutions, so that the purification was expected to be feasible. However, it was pointed out that glucose retention is significantly lower in mixed-solute solutions, i.e. as far as lactate is present. This decrease is such that retentions of both solutes become comparable so that any purification is unachievable. Experiments at different salt concentrations and with a salt of different nature (mineral salt - $\mathrm{NaCl}$ ) were also performed. Again, it was found that the presence of $\mathrm{NaCl}$ tends to decrease glucose retention. Moreover, the phenomenon is shown to be related to salt concentration in both cases, i.e. with sodium lactate and $\mathrm{NaCl}$. Some 
possible explanations of this effect are provided in this paper. Further investigations are still in progress to improve the knowledge of the involved mechanisms.

Keywords: Nanofiltration; Lactic acid; Intrinsic retention; Salt and sugar retention; Hydration

* Corresponding author: Laboratoire de Génie Chimique, Université Paul Sabatier, 118 Route de Narbonne, 31062 Toulouse cedex, France, Tel: 33 (0)5 615576 19, Fax: 33 (0)5 615576 19, E-mail: bouchoux@chimie.ups-tlse.fr

\section{Introduction}

Nanofiltration (NF) is known to be a separation technique lying between ultrafiltration (UF) and reverse osmosis (RO) which presents a selectivity governed both by steric hindrance effects and electrostatic repulsions. Most NF membranes have therefore the particularity to strongly retain compounds of molecular weight up to $150-250 \mathrm{~g} \cdot \mathrm{mol}^{-1}$ and charged species, especially multivalent ions.

Due to these interesting separation properties, NF begins to be used in a wide range of applications in the food industry as dairy by-product treatment [1, 2], fruit juice production [3], or sugar beet press water clarification [4]. Moreover, according to the numerous works published in the last years, the use of NF as a downstream operation in organic acids production processes is expected to be a large and new application field of this technology [5$10]$.

Organic acids (acetic, lactic, gluconic acids...), which are increasingly used in food industries, are mainly produced by fermentation. This fermentation generates a broth containing the acid salt (sodium, ammonium or calcium salt) and different impurities, like 
residual sugars and mineral salts. Different operations of purification, concentration and conversion are then required in order to get the acid in a suitable form $[11,12]$. The integration of NF in such processes can be investigated at different stages depending on the organic acid considered. On the one hand, for high molecular weight organic acids, NF can be considered as a concentration step. The concentration of model solution of ammonium fumarate by NF or RO was already achieved [5]. It was also pointed out that the use of NF to concentrate organic acid salts, as sodium citrate or gluconate, could present the advantage to overcome the concentration upper limit reached by $\mathrm{RO}[6,7]$. On the other hand, NF can constitute a purification step in the case of low molecular weight organic acids. It was shown for instance that NF is an appropriate method for downstream processing of sodium acetate fermentation broths thanks to its ability to let permeate the acetate while retaining nutriments, like glucose, that can be recycled to the fermentation tank [8].

In the present work, the possibility of using NF to achieve the purification of a sodium lactate fermentation broth, i.e. a partial glucose elimination, is investigated. The specificity of such a study rests on the nature of the fluid, which is a mixed-solute solution of an electrolyte (sodium lactate) and a non-electrolyte (glucose). Such a kind of mixture was rarely studied in NF. In the few references available, differences between retentions obtained with each solute taken separately and those obtained with mixtures were reported. A decrease of the salt retention in presence of a neutral solute was generally observed [13-15]. Some attempts were made to explain these observations, like an increasing viscosity near the membrane surface due to the presence of the neutral solute which leads to a higher concentration polarization of the salt [13]. Conversely, the results concerning the effect of a charged solute on the retention of a neutral solute are much more contradictory. Indeed, while a decrease of lactic acid or glucose retention was reported in presence of $\mathrm{NaCl}[16,17]$, other authors found an opposite effect with solutions of lactose / $\mathrm{NaCl}$ and lactic acid / $\mathrm{NaCl}[14,15,18]$. It is hardly feasible 
to draw any general tendency from these results, since they were obtained in different conditions, i.e. with different membranes and at variable concentrations.

Nevertheless, it clearly demonstrates the necessity to carry out more systematic work, as that presented in this paper. The experimental investigation reported here was indeed performed with solutions of increasing complexity, i.e. single-solute solutions of glucose and sodium lactate on the one hand and mixed-solute (binary) solutions on the other hand. Experiments with mixtures of $\mathrm{NaCl}$ and glucose were also carried out to investigate the influence of the salt nature.

\section{Experimental materials and methods}

\subsection{Membrane and chemicals}

The Desal 5 DK NF membrane was used. Supplied by Osmonics as flat sheets, this membrane is made of polyamide (active layer) and polysulfone and is negatively-charged at $\mathrm{pH}$ greater than 4 [19]. Its average characteristics, provided by the supplier, are an average molecular weight cut-off of $150-300$ g.mol ${ }^{-1}$, a $98 \%$ retention of $\mathrm{Mg}_{2} \mathrm{SO}_{4}$ (at $\left[\mathrm{Mg}_{2} \mathrm{SO}_{4}\right]=2$ g. $1^{-1}$ and $\Delta p=6.9$ bar), and an hydraulic permeability of approximately $5.51 \cdot \mathrm{h}^{-1} \cdot \mathrm{m}^{-2} \cdot \mathrm{bar}^{-1}$.

Solutions were prepared using high purity sodium lactate (Prolabo - Merck Eurolab), sodium chloride (Prolabo - Merck Eurolab), glucose (Acros Organics) and lactic acid (Acros Organics) dissolved in ultra-pure water. The relevant characteristics of these compounds are listed in Table 1.

\subsection{Analytical methods}


Sodium lactate (NaLac), glucose (Glu) and lactic acid (HLac) concentrations for singlesolute solutions were determined by refractometry (Atago RX-5000 refractometer). Sodium lactate, sodium chloride and glucose concentrations for mixed-solute solutions were determined by high-performance liquid chromatography using a Shodex SUGAR SH1011 column (Showa Denko) and a refractive index detector. Column temperature was set to $50^{\circ} \mathrm{C}$, and the mobile phase was $0.01 \mathrm{~N}$ sulfuric acid at a flow rate of $1 \mathrm{ml} \cdot \mathrm{min}^{-1}$. Mixtures of the two solutes at different concentrations were used for the calibration.

\subsection{Experimental procedure}

Fig.1 is a schematic diagram of the cross-flow filtration unit used in this work. Experiments were carried out with the Osmonics Sepa CF II cell which uses flat sheet membranes of $137 \mathrm{~cm}^{2}$. The solution is pumped from a five litres feed vessel kept at $25 \pm 0.5$ ${ }^{\circ} \mathrm{C}$ into the cell and flows tangentially to the membrane. A stainless steel control valve is mounted on the retentate outlet to control the transmembrane pressure, which is monitored through two digital manometers located on the inlet and outlet of the cell. The retentate and the permeate were recycled into the feed vessel in order to work at constant feed concentration. Permeate samples were taken through a by-pass mounted on the permeate outlet.

The concentrations of the solutions used in the present study are listed in Table 2. Experiments were performed at cross-flow velocities varying from 0.33 to $1.33 \mathrm{~m} . \mathrm{s}^{-1}$ and at transmembrane pressures from 2 to 20 bar. A volume of $5 \mathrm{ml}$ of permeate was collected for each pressure and timed to estimate the permeation flux. The permeate concentrations $c_{p}$ were determined by the analytical methods previously presented, while the retentate concentrations $c_{r}$ were calculated from a mass balance by considering the feed concentration as constant. 
A membrane presenting a visible mechanical damage or an abnormally high water flux (more than $20 \%$ difference between two consecutive permeability measurements) was replaced by a new one.

\subsection{Membrane pre-treatment}

In order to get an adequate reference state before each experiment, Desal $5 \mathrm{DK}$, like most of NF membranes, need to be pre-treated at elevated pressure [20]. In this work, the membrane was compacted before each experiment by filtering high-purity water at 20 bar until reaching a constant permeation flux $J_{v}$. Then, the mean hydraulic permeability $L_{p 0}$ was calculated from $n$ permeation fluxes $J_{v, i}$ obtained at $n$ transmembrane pressures $\Delta p_{i}$ from 2 to 20 bar according to this equation :

$L_{p 0}=\frac{\sum_{i=1}^{n} \frac{J_{v, i}}{\Delta p_{i}}}{n}$

Fig.2 shows the variation of hydraulic permeability versus the number of experiments for six membrane samples used in this study. Two observations can be made regarding to these results. On the one hand, the initial hydraulic permeabilities ( $L_{p 0}$ for the first experiment) of all samples are similar. Initial $L_{p 0}$ varies from 5 to $71 . \mathrm{h}^{-1} \cdot \mathrm{m}^{-2} \cdot$ bar ${ }^{-1}$, which is in accordance with the value given by the supplier. On the other hand, all samples showed an increase of the hydraulic permeability as experiments were carried out. This increase is of different magnitude depending on the sample but no correlation was stated with the type of solution investigated. However, it shows that no irreversible fouling occurred.

\subsection{Data treatment - Concentration polarization}


Because of concentration polarization, two different parameters can be used to describe the membrane retention, i.e. the observed retention, $R_{o b s}$, and the intrinsic retention, $R_{\text {int }}$ :

$$
R_{o b s}=1-\frac{c_{p}}{c_{r}}
$$

$$
R_{\mathrm{int}}=1-\frac{c_{p}}{c_{m}}
$$

where $c_{p}$ and $c_{r}$ stand for the permeate and retentate concentrations respectively and $c_{m}$ is the concentration at the membrane surface.

Fig.3 shows the theoretical variations of $R_{o b s}$ and $R_{\text {int }}$ with the permeation flux. The observed retention $R_{o b s}$ is an experimentally measured value, providing the filtration performance for a given run. $R_{o b s}$ is however strongly dependent on concentration polarization and consequently changes with the hydrodynamic conditions near the membrane. Such a dependence is illustrated by the decrease of $R_{o b s}$ after reaching a maximum on Fig.3. The intrinsic retention $R_{\text {int }}$, also called the "real retention", deals directly with the concentration at the membrane surface $c_{m}$. Contrary to $R_{o b s}, R_{\text {int }}$ increases gradually with $J_{v}$ until reaching a constant value $R_{\infty}$. Because it leaves the concentration polarization phenomenon out of account, $R_{\text {int }}$ represents a relevant characteristic parameter of the system solute/solution/membrane in term of selectivity. It is then often preferred to $R_{o b s}$ as far as the investigation of the mass transfer mechanisms is concerned. Further results will consequently be presented as variation of the intrinsic retention versus permeation flux.

Since the direct calculation of $R_{\text {int }}$ from equation (3) requires the knowledge of $c_{m}$, that cannot be obtained experimentally, different methods were proposed to calculate $R_{\text {int }}$ from the observed retention. Among these methods, the "velocity variation method" is generally recognized as the most appropriate [21]. This method, which is used in this paper, is 
summarized below. It is based on the description of the concentration polarization phenomenon by the film theory, which gives:

$$
\ln \left(\frac{1-R_{o b s}}{R_{o b s}}\right)=\ln \left(\frac{1-R_{\mathrm{int}}}{R_{\mathrm{int}}}\right)+\frac{J_{v}}{k}
$$

The mass transfer coefficient $k$ can most generally be calculated from Sherwood relations of the type:

$S h=\frac{k d_{h}}{D}=a R e^{b} S c^{0.25}$

with $d_{h}$ the hydraulic diameter and $\mathrm{D}$ the diffusivity of the involved solute. The adjustable parameters $a$ and $b$ are respectively equal to 0.023 and 0.875 for turbulent conditions (Deissler expression).

This last relation shows a dependence between the mass transfer coefficient $k$ and the crossflow velocity $v$ that can be expressed as:

$k=\frac{1}{c} v^{b}$

with $c=\frac{1}{a} d_{h}^{(1-b)} D^{-0.75} \rho^{(0.25-b)} \mu^{(b-0.25)}$

where $\rho$ and $\mu$ are respectively the solution density and the dynamic viscosity. As variations of properties in the polarisation layer exist (increase of viscosity and changes in diffusivity and density as a result of increasing concentration near the membrane), these values are those corresponding to the mean concentration in the polarization layer.

Combining equation (4) and (6), we obtain:

$\ln \left(\frac{1-R_{\text {obs }}}{R_{\text {obs }}}\right)=\ln \left(\frac{1-R_{\mathrm{int}}}{R_{\mathrm{int}}}\right)+c \frac{J_{v}}{v^{0.875}}$ 
It is then assumed that $\mathrm{c}$ is independent of the polarization level, and can be considered as independent of the cross-flow velocity and permeation flux. Van den Berg and al. showed that this assumption can reasonably be made and leads to satisfactory results [21].

Consequently, at a given flux $J_{v, i}$, the variation of $\ln \left(\frac{1-R_{o b s}\left(J_{v, i}\right)}{R_{o b s}\left(J_{v, i}\right)}\right)$ as a function of $\frac{J_{v, i}}{v^{0.875}}$ (i.e. at different cross-flow velocities $v$ ) should provide a straight line of slope c, from the y-intercept of which $R_{\text {int }}\left(J_{v, i}\right)$ can be calculated. The variation of $R_{\text {int }}$ with $J_{v}$ can be obtained by repeating this procedure for different values of $J_{v}$.

This is illustrated in Fig.4 taking the results obtained with a $0.25 \mathrm{M}$ sodium lactate solution on membrane sample $\mathrm{A}$ as an example. Each set of points corresponds to experimental values of $R_{o b s}$ obtained at different cross flow velocities and at a constant permeation flux. These sets are then fitted by straight lines of identical slope and $R_{\text {int }}$ is calculated. Fig.5 provides the experimental variations of $R_{o b s}$ versus the flux $J_{v}$ together with that calculated for $R_{\text {int }}$ from the results presented in Fig.4.

Such a method was used to treat the results of both single- and mixed-solute solutions experiments. In the last case, the method is applied to each solute independently.

\section{Results and discussion}

Experiments were carried out with solutions of different composition, i.e. single-solute ones, containing sodium lactate or glucose, and mixed-solute ones, containing variable proportions of both. The different membrane sheets used are first of all characterized in term of charge density and mean pore radius using relevant single-solute retention results. The glucose and sodium lactate retentions obtained with single- and mixed-solute solutions are 
then successively presented in details. Any possible interaction between the solutes in mixedsolute solutions are investigated by comparing the two series of experiments. As previously explained, all the results are provided as variations of the intrinsic retention, $R_{\text {int }}$, versus the permeation flux, $J_{v}$.

\subsection{Membrane characterization}

Fig.6 presents the $R_{\text {int }}$ plots obtained for a single-solute solution of glucose $0.1 \mathrm{M}$ with three different membrane samples D, E and F. We can observe that the retention differs significantly from one membrane to another. For instance at $J_{v}=2.5 \times 10^{-5} \mathrm{~m}^{3} \cdot \mathrm{m}^{-2} \cdot \mathrm{s}^{-1}$, the retention varies from 0.7 (membrane E) to 0.9 (membrane F). Since glucose is considered as a "neutral" solute, its retention comes from steric effects only. Glucose retention depends consequently on its hydrodynamic radius $(\approx$ Stokes radius) and on the mean pore size of the membrane. Such variations as those shown on Fig.6 are therefore due to variations of the mean pore size between the membrane samples. Different models were developed to calculate the mean pore radius $r_{p}$ from the rejection data obtained with an uncharged solute. For nanofiltration, Bowen and al. recently introduced a simplified model obtained from the finite difference linearization of pore concentration gradient [22]. In the case of an uncharged solute, it presents the advantage of using $r_{p}$ as the only independent parameter. The values of the mean pore radius obtained from the glucose retention (Fig.6) for the different membrane samples are reported in Table 3. One can observe that $r_{p}$ varies from $0.52 \mathrm{~nm}$ (membrane F) to $0.63 \mathrm{~nm}$ (membrane E). These values are systematically higher than those reported by Wang, Bowen and Straatsma for the same membrane, i.e. respectively $0.40,0.43$ and 0.46 $\mathrm{nm}[22-24]$. 
Such variations of the solute retention from a membrane sample to another are still more visible regarding sodium lactate results. Fig.7 shows the retentions obtained for a $0.5 \mathrm{M}$ sodium lactate solution with the three membranes D, E and F. One can observe that retention difference can reach up to $600 \%$ from membrane $\mathrm{F}$ to membrane $\mathrm{D}\left(J_{v}=0.5 \times 10^{-5} \mathrm{~m}^{3} \cdot \mathrm{m}^{-2} \cdot \mathrm{s}^{-1}\right)$. Sodium lactate is a dissociated specie, i.e. a negatively charged solute. Then, its retention comes from the combination of steric effects and electrostatic repulsions due to the charges carried by the membrane. According to the former model [22] the retention of a charged solute can be described using two independent parameters, the pore radius $r_{p}$ and the effective membrane charge density $X_{d}$. Because the model does not require any numerical integration, $X_{d}$ can easily be calculated from the retention results by using the previously calculated mean pore radii (see Table 3). Electrostatic repulsions can be described through a Donnan potential term, combined or not with a dielectric exclusion term [25]. Because it leaded in most cases in an overestimation of the retention, dielectric exclusion was not taken into account in our calculations. Anyway, it is impossible to obtain the accurate contribution of dielectric exclusion to electrostatic repulsions without complementary experiments [22]. It is to be noted here that the $X_{d}$ values reported in Table 3 do not correspond to an intrinsic characteristic of the membrane. It is indeed known that the membrane charge density depends on the considered salt and on its concentration [24, 25], and also on the $\mathrm{pH}$ of the solution (See [26] for instance). However, for a same given solution, i.e. NaLac at $0.5 \mathrm{M}$, Table 3 reveals that each membrane samples show different charge densities from -378 to -2258 mol.m $\mathrm{m}^{-3}$

Because of the variabilities pointed out here, the results obtained on different membranes samples have to be distinguished (see section 3.2 and 3.3). As a matter of fact, such results show that different membrane samples, even corresponding to a unique given commercial reference, can exhibit quite large disparities in terms of physical properties (pore 
radius and charge density). As far as a process evaluation is investigated, such variabilities have to be considered carefully.

\subsection{Single-solute solutions}

Fig.8 shows the variations of the intrinsic retentions of glucose versus $J_{V}$ for two different concentrations, i.e. 0.05 and $0.1 \mathrm{M}$. One can state that the intrinsic retention is almost independent from the glucose concentration. This classical behaviour of an uncharged solute in membrane filtration comes from the fact that only steric-hindrance effects are responsible of the retention. On the other hand, Fig.9 shows the sodium lactate retention curves obtained with solutions at different concentrations on the same membrane. One can state that in that case, decreasing retentions are obtained for increasing concentrations. Indeed, in such conditions, the retention of sodium lactate, which is negatively charged, results from the combination of steric effects and electrostatic interactions between the membrane and the solute. For a low solute concentration compared to the membrane charge density, electrostatic repulsion are predominant so that high retentions are obtained. As the feed concentration increases, electrostatic interactions become weaker and the retention decreases. The lowest retention value is thus reached when electrostatic repulsions become negligible compared to steric-hindrance effects. Such a dependence of the retention of charged solute versus the concentration was already reported by different authors [27-30] and is generally explained according to the Donnan theory [31]. The retention obtained with a $0.25 \mathrm{M}$ lactic acid solution is also reported on Fig.9. Because lactic acid is the uncharged form of sodium lactate, its retention represents the lower limit of the sodium lactate one.

All these tendencies, obtained on membrane $\mathrm{D}$, were also found on membrane $\mathrm{E}$ and $\mathrm{F}$ (results not shown). Moreover, these single-solute retention results show that, despite the 
variabilities pointed out in section 3.1, glucose retention is in all cases larger than sodium lactate one at concentrations of a fermentation broth (between 0.5 and $1 \mathrm{M}$ of NaLac).

\subsection{Mixed-solute solutions}

Experiments were carried out and mixed-solute solutions of NaLac and glucose at concentrations listed in Table 2. Fig.10 and 11 shows respectively the variations of the sodium lactate and glucose retentions versus $\mathrm{J}_{\mathrm{V}}$ obtained at a given mixture composition for the three membranes D, E and F. The results obtained with the single-solute solutions at the same concentrations are also shown for comparison.

As far as sodium lactate is concerned, one can observe (Fig.10) that quite identical values are obtained with membranes $\mathrm{D}$ and $\mathrm{F}$ for the single and mixed solutions. A slight variation, which is not significant, is observed with membrane E. Consequently, the retention for sodium lactate is not influenced, at least for the conditions investigated, by the presence of glucose.

On the contrary, Fig.11 shows that the retention of glucose is strongly affected by the presence of sodium lactate. Indeed, for any membrane, the retention obtained with the mixedsolution is lower than that obtained with the single-solute solution of glucose. This decrease is more or less important depending on the membrane. As a matter of fact, glucose retention, which seemed high enough according to single-solution results, is finally not sufficient to permit a partial purification. Comparison between Fig.10 and 11 shows that, for each membrane sample, glucose retention is too close to sodium lactate one to get an efficient separation.

In order to check to what extend such a variation of glucose retention in the presence of a salt can be generalised, experiments were carried out with solutions containing $\mathrm{NaCl}$ instead 
of sodium lactate at the same concentrations. The results obtained for the glucose retention are plotted in Fig.12. One can state that, at least with membranes D and F, the glucose retention is lower in the presence of $\mathrm{NaCl}$. This decrease is less pronounced than that obtained with sodium lactate. No visible influence of the presence of $\mathrm{NaCl}$ comes out with membrane E. One can obverse that this membrane is that for which the lowest decrease was obtained with sodium lactate (See Fig.11).

Then, from the qualitative point of view, former results show that the retention of glucose decreases in the presence of salt. This decrease depends on the nature of the salt as well as on the membrane characteristics. From the quantitative point of view, it can be evaluated using the following variable $\alpha$, which depends on the flux, defined as :

$$
\alpha\left(J_{v}\right)=1-\frac{R_{i n t, G l u}^{\prime}\left(J_{v}\right)}{R_{i n t, G l u}\left(J_{v}\right)}
$$

where $R_{\text {int }}$ and $R_{\text {int }}^{\prime}$ stand respectively for the retentions obtained in single- and mixed-solute solutions. $\alpha$ is maximum for the lowest fluxes and decreases with increasing flux. The range of variation does not exceed $20 \%$. Then, for comparison, the values obtained for a given flux are provided in Table 4. This table clearly highlights that, for any salt, the glucose retention decrease is the more important with membrane $\mathrm{D}$ and the less important for membrane $\mathrm{E}$. Membrane F shows an intermediate behaviour. Moreover, the alpha values obtained with a same membrane are always larger for mixed-solute solutions containing sodium lactate. This illustrates the fact, already pointed out, that the phenomenon is less marked with $\mathrm{NaCl}$.

In order to study the influence of the fluid composition on the NF performances, experiments were carried out with mixtures containing different concentrations of glucose and sodium lactate. For a given sodium lactate concentration, comparable glucose retentions were obtained for the two glucose concentrations investigated $([\mathrm{Glu}]=0.05$ and $0.1 \mathrm{M}$ - results not shown). On the other hand, Fig.13 and 14 show the variation of the glucose retention versus 
the flux obtained for a given glucose concentration at different salt concentrations. One can state that in any case, glucose retention decreases with increasing salt concentration. The corresponding alpha values are reported in Table 4.

\subsection{Summary and discussion}

The experimental investigation shows that glucose retention is strongly affected by the presence of sodium lactate. From the qualitative point of view, the apparition of such a phenomenon is in accordance with former observations showing that the retention of a uncharged solute decreases in the presence of a charged one [16, 17]. However, the phenomenon is clearly stronger in our case. This difference is probably due to the type of solutes and concentrations used. The charged solute used by these authors is indeed the sodium chloride $\mathrm{NaCl}$ and it was shown here that sodium lactate has a stronger effect on glucose retention than this mineral salt. Moreover, it was shown that a high concentration of charged solute induces a stronger decrease of glucose retention and Wang and al. [17] used relatively low $\mathrm{NaCl}$ concentrations compared to the present study $(0.1 \mathrm{M}$ against 0.5 to $1 \mathrm{M}$ here). Furthermore, the conclusions of these previous works were drawn by considering the variations of retention versus the transmembrane pressure. This approach does not take into account the additional osmotic pressure due to the addition of a salt. It consequently does not permit a rigorous comparison between the retentions obtained at different fluid compositions. This comparison can only be done at a same permeation flux, i.e. at a same convective flux, as it is done in the present study.

The observed phenomenon can be explained by several hypothesis. It was shown here that the intrinsic retention of glucose (retention at no concentration polarization) decreases in the presence of a salt. An explanation based on interactions in the polarization layer, like the 
one proposed by Vellenga and al. for instance [13], is therefore inappropriate to our case. Plausible explanations are more probably related to glucose size exclusion. According to this postulate, the decrease of glucose retention can be imputed to an increase of membrane mean pore radius, a decrease of the glucose hydrodynamic radius, or a combination of the two phenomena.

Pore swelling (increase of pore radius) may be qualitatively explained by variations of membrane charge density through the following hypothesis. As already pointed out in section 3.1 , the charge density of nanofiltration membranes depends on many parameters $(\mathrm{pH}$, salt nature and salt concentration). As the $\mathrm{pH}$ was sensibly constant in all the solutions used (between 6.5 and 7), only the presence of a salt may be responsible for the change in membrane charge density in our case. It is indeed known that adding a salt in solution leads to an increase of membrane charge density [19] and consequently an increase of the counter-ions concentration in the electrical double-layer at the pores surface. This phenomenon, by inducing higher repulsions forces inside the pores, may result in pore swelling. Moreover, absolute membrane charge density generally increases with salt concentration (it can be related to the salt concentration through a Freundlich isotherm for instance [24]). This could explain why glucose retention still decreases when salt concentration increases. To some extend, the higher retention decrease encountered with sodium lactate compared to sodium chloride could also be explain by this type of analysis (i.e. a same concentration of sodium lactate leads to a higher charge of the membrane compared to $\mathrm{NaCl}$ ). However, the relations between salt nature and membrane charge density are still relatively unknown.

On the other hand, the decrease of glucose hydrodynamic radius may be described through direct interactions between the solutes in the bulk. In a mixed-solute solution of glucose and a salt, water will indeed preferentially solvate the salt to the detriment of glucose ("salting-out" effect). Glucose, therefore less hydrated, may consequently present a lower 
apparent volume than in absence of a salt and permeates more freely through the membrane. In the same manner as previously, this hypothesis is in agreement with the variations of glucose retention as a function of the salt nature and concentration. This "salting-out" effect is indeed related to the salt concentration and is all the more important as the concentration increases. Moreover, because salts of different nature are more or less solvated by water, the corresponding salt effect is expected to differ from one salt to another. The fact that glucose is more retained in presence of sodium lactate than in presence of sodium chloride could therefore be explained by a stronger hydration of lactate ion compared to chloride ion. Further investigations are however needed to confirm this last assumption.

\section{Conclusion}

The possibility of using NF to achieve a partial glucose elimination from a sodium lactate fermentation broth was investigated. The evaluation of the separation efficiency glucose / sodium lactate by nanofiltration was carried out with membrane Desal 5 DK. A first series of experiments was done with single-solute solutions of each solute. The effect of concentration on their retention was investigated. It was shown that, despite the variabilities existing between different membrane samples, glucose retention is in all cases larger than sodium lactate one at concentrations of a fermentation broth $(0.05-0.1 \mathrm{M}$ of glucose and $0.5-1$ $\mathrm{M}$ of NaLac). A second series of experiments, carried out with mixtures of both solutes, provided quite different results. It was indeed observed that, as sodium lactate retention is unchanged, glucose retention strongly decreases. This decrease is such that the retentions of both solutes are comparable and that the separation becomes more difficult and even unachievable. Further experiments at different salt concentrations and with a salt of different 
nature $(\mathrm{NaCl})$ were also performed. It was shown that the glucose retention decrease is more important in presence of the organic salt and increases with salt concentration.

The decrease of a neutral solute retention in presence of a charged one is probably a general problem in nanofiltration of complex fluids (like those of the food industry). It is thus absolutely necessary to identify the involved mechanisms. Some possible explanations are presented in this paper. Further investigations are in progress in order to completely understand the phenomenon.

\section{Acknowledgements}

This research was carried out under funding from the PROSETIA program (CNRS/INRA). The authors would like to thank J.C. Rouch for setting up the pilot unit and Prof. B. Chaufer for the fruitful scientific discussions. 


\section{Nomenclature}

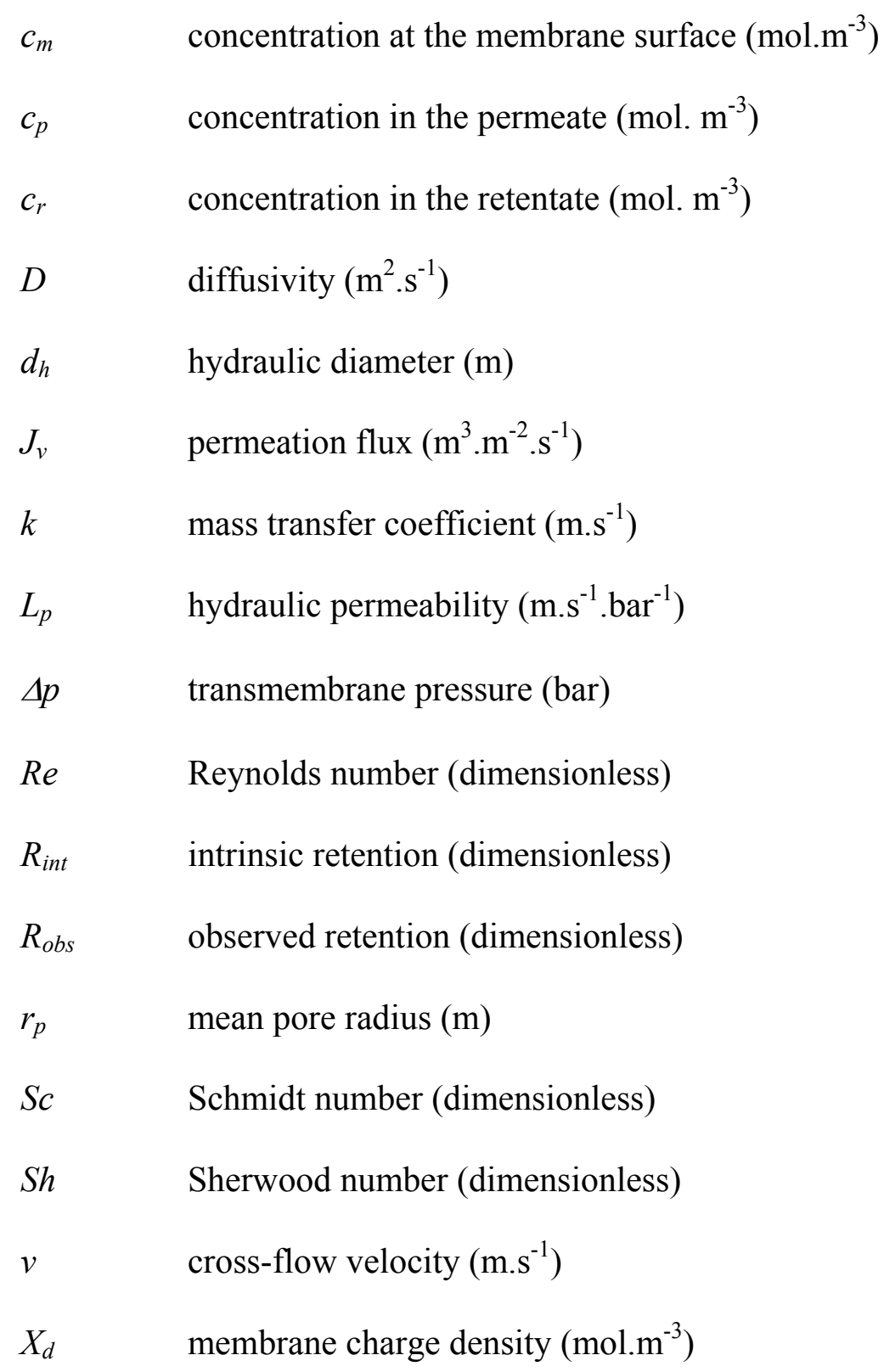

\section{Greek letters}

$\alpha \quad$ glucose retention decrease (dimensionless)

$\mu \quad$ solution dynamic viscosity (Pa.s)

$\rho \quad$ density $\left(\mathrm{kg} \cdot \mathrm{m}^{-3}\right)$ 


\section{References}

[1] M. Nguyen, N. Reynolds, S. Vigneswaran, By-product recovery from cottage cheese production by nanofiltration, Journal of Cleaner Production 11 (2003) 803-807.

[2] H.C. Van der Horst, J.M.K. Timmer, T. Robbertsen, J. Leenders, Use of nanofiltration for concentration and demineralization in the dairy industry: Model for mass transport, Journal of Membrane Science 104 (1995) 205-218.

[3] R. Ferrarini, A. Versari, S. Galassi, A preliminary comparison between nanofiltration and reverse osmosis membranes for grape juice treatment, Journal of Food Engineering $50(2001) 113-116$.

[4] A. Hinkova, Z. Bubnik, P. Kadlec, J. Pridal, Potentials of separation membranes in the sugar industry, Separation and Purification Technology 26 (2002) 101-110.

[5] M. Moresi, B. Ceccantoni, S. Lo Presti, Modelling of ammonium fumarate recovery from model solutions by nanofiltration and reverse osmosis, Journal of Membrane Science 209 (2002) 405-420.

[6] S. Lo Presti, M. Moresi, Recovery of sodium gluconate from model solutions by reverse osmosis, Journal of Food Engineering 44 (2000) 109-117.

[7] S. Lo Presti, M. Moresi, Recovery of selected microbial metabolites from model solutions by reverse osmosis, Journal of Membrane Science 174 (2000) 243-253.

[8] I.S. Han, M. Cheryan, Nanofiltration of model acetate solutions, Journal of Membrane Science 107 (1995) 107-113.

[9] J.M.K. Timmer, H.C. van der Horst, T. Robbertsen, Transport of lactic acid through reverse osmosis and nanofiltration membranes, Journal of Membrane Science 85 (1993) 205-216. 
[10] J.M.K. Timmer, J. Kromkamp, T. Robbertsen, Lactic acid separation from fermentation broths by reverse osmosis and nanofiltration, Journal of Membrane Science 92 (1994) 185-197.

[11] M. Bailly, Production of organic acids by bipolar electrodialysis: realizations and perspectives, Desalination 144 (2002) 157-162.

[12] M. Bailly, H. Roux-de Balmann, P. Aimar, F. Lutin, M. Cheryan, Production processes of fermented organic acids targeted around membrane operations: design of the concentration step by conventional electrodialysis, Journal of Membrane Science 191 (2001) 129-142.

[13] E. Vellenga, G. Tragardh, Nanofiltration of combined salt and sugar solutions: coupling between retentions, Desalination 120 (1998) 211-220.

[14] F.J. Sapienza, W.N. Gill, M. Soltanieh, Separation of ternary salt/acid aqueous solutions using hollow fiber reverse osmosis, Journal of Membrane Science 54 (1990) 175-189.

[15] D. Szaniawska, H.G. Spencer, Non-equilibrium thermodynamics analysis of the transport properties of formed-in-place $\mathrm{Zr}(\mathrm{IV})$ hydrous oxide-polyacrylate membranes: III. Ternary lactose-NaCl-water solutions, Desalination 113 (1997) 1-6.

[16] V. Freger, T.C. Arnot, J.A. Howell, Separation of concentrated organic/inorganic salt mixtures by nanofiltration, Journal of Membrane Science 178 (2000) 185-193.

[17] X.-L. Wang, C. Zhang, P. Ouyang, The possibility of separating saccharides from a $\mathrm{NaCl}$ solution by using nanofiltration in diafiltration mode, Journal of Membrane Science 204 (2002) 271-281.

[18] U. Kulozik, H.G. Kessler, Effects of salt ions and deposit formation on the permeation of organic molecules in complex media in reverse osmosis, Journal of Membrane Science 54 (1990) 339-354. 
[19] G. Hagmeyer, R. Gimbel, Modelling the salt rejection of nanofiltration membranes for ternary ion mixtures and for single salts at different $\mathrm{pH}$ values, Desalination 117 (1998) 247-256.

[20] M. Manttari, A. Pihlajamaki, E. Kaipainen, M. Nystrom, Effect of temperature and membrane pre-treatment by pressure on the filtration properties of nanofiltration membranes, Desalination 145 (2002) 81-86.

[21] G.B. van den Berg, I.G. Racz, C.A. Smolders, Mass transfer coefficients in cross-flow ultrafiltration, Journal of Membrane Science 47 (1989) 25-51.

[22] W.R. Bowen, T.A. Doneva, P.M. Williams, Linearized transport model for nanofiltration : development and assessment, AIChE Journal 48 (2002) 760-773.

[23] X.-L. Wang, T. Tsuru, M. Togoh, S. Kimura, Transport of organic electrolytes with electrostatic and steric effects through nanofiltration membranes, Journal of Chemical Engineering of Japan 28 (1995) 372-380.

[24] J. Straatsma, G. Bargeman, H.C. van der Horst, J.A. Wesselingh, Can nanofiltration be fully predicted by a model?, Journal of Membrane Science 198 (2002) 273-284.

[25] W.R. Bowen, J.S. Welfoot, Modelling the performance of membrane nanofiltration-critical assessment and model development, Chemical Engineering Science 57 (2002) 1121-1137.

[26] G. Hagmeyer, R. Gimbel, Modelling the rejection of nanofiltration membranes using zeta potential measurements, Separation and Purification Technology 15 (1999) 19-30.

[27] T. Tsuru, M. Urairi, S.-I. Nakao, S. Kimura, Negative rejection of anions in the loose reverse osmosis separation of mono- and divalent ion mixtures, Desalination 81 (1991) 219-227. 
[28] J. Schaep, C. Vandecasteele, A. Wahab Mohammad, W. Richard Bowen, Modelling the retention of ionic components for different nanofiltration membranes, Separation and Purification Technology 22-23 (2001) 169-179.

[29] Y. Xu, R.E. Lebrun, Investigation of the solute separation by charged nanofiltration membrane: effect of $\mathrm{pH}$, ionic strength and solute type, Journal of Membrane Science 158 (1999) 93-104.

[30] X.-L. Wang, T. Tsuru, M. Togoh, S.-I. Nakao, S. Kimura, Evaluation of pore structure and electrical properties of nanofiltration membranes, Journal of Chemical Engineering of Japan 28 (1995) 186-192.

[31] F.G. Donnan, Theory of membrane equilibria and membrane potentials in the presence of non-dialysing electrolytes. A contribution to physical-chemical physiology, Journal of Membrane Science 100 (1995) 45-55. 
Table 1: Principal characteristics of investigated compounds.

\begin{tabular}{|c|c|c|c|c|}
\hline Compounds & Formula & $\begin{array}{l}\text { Molecular weight } \\
\left(\text { g.mol }{ }^{-1}\right)\end{array}$ & $\begin{array}{l}\text { Diffusivity D } \\
\left(10^{-10} \mathrm{~m}^{2} \cdot \mathrm{s}^{-1}\right)\end{array}$ & $\begin{array}{l}\text { Stokes radius } \\
\mathrm{r}_{\mathrm{s}}(\mathrm{nm})\end{array}$ \\
\hline Glucose & & 180.16 & 6.9 & 0.365 \\
\hline Lactic acid & & 90.08 & 11 & 0.22 \\
\hline $\mathrm{Na}^{+}$ & - & 22.99 & 13.3 & 0.184 \\
\hline Lactate & & 89.07 & 10.6 & 0.23 \\
\hline $\mathrm{Cl}^{-}$ & - & 35.45 & 20.3 & 0.121 \\
\hline
\end{tabular}


Table 2: Solutions used $\left(\mathrm{M}=\right.$ mol. $\left.\mathrm{L}^{-1}\right)$.

\begin{tabular}{lll}
\hline $\begin{array}{l}\text { Single-solute } \\
\text { solutions }\end{array}$ & Glucose (Glu) & $0.05 \mathrm{M}-0.1 \mathrm{M}$ \\
& Sodium lactate (NaLac) & $0.1 \mathrm{M}-0.25 \mathrm{M}-0.5 \mathrm{M}-1 \mathrm{M}$ \\
& Lactic acid (HLac) & $0.25 \mathrm{M}$ \\
\hline $\begin{array}{l}\text { Mixed-solute } \\
\text { solutions }\end{array}$ & Glu / NaLac & $0.1 \mathrm{M} / 0.5 \mathrm{M}-0.1 \mathrm{M} / 1 \mathrm{M}$ \\
& Glu / NaCl & $0.1 \mathrm{M} / 0.5 \mathrm{M}-0.1 \mathrm{M} / 1 \mathrm{M}$ \\
\hline
\end{tabular}


Table 3: Mean pore radius $\left(r_{p}\right)$ and membrane charge density $\left(X_{d}\right)$ obtained from the linearized transport model $[22,25]$.

\begin{tabular}{lll}
\cline { 2 - 3 } & $\begin{array}{l}\text { One-parameter } \\
\text { model }\end{array}$ & $\begin{array}{l}\text { Two-parameter model } \\
\text { - without dielectric exclusion }\end{array}$ \\
\cline { 2 - 3 } & $r_{p}(\mathrm{~nm})$ & $X_{d}\left(\mathrm{~mol}^{-3}\right)$ \\
\hline Membrane D & 0.57 & -378 \\
Membrane E & 0.63 & -1511 \\
Membrane F & 0.52 & -2258 \\
\hline
\end{tabular}


Table 4: Glucose retention decrease ( $\alpha$, defined by eq.(9)) in presence of a sodium salt ( $\mathrm{NaLac}$ or $\mathrm{NaCl})$ at two concentrations by comparison with glucose retention in single-solute solutions at $[\mathrm{Glu}]=0.1 \mathrm{M}$.

\begin{tabular}{lcccccccc} 
& \multicolumn{2}{c}{$+\mathrm{NaLac} 0.5 \mathrm{M}$} & \multicolumn{2}{c}{$+\mathrm{NaLac} 1 \mathrm{M}$} & \multicolumn{2}{c}{$+\mathrm{NaCl} 0.5 \mathrm{M}$} & \multicolumn{2}{c}{$+\mathrm{NaCl} 1 \mathrm{M}$} \\
& $\alpha_{\min }$ & $\alpha_{\max }$ & $\alpha_{\min }$ & $\alpha_{\max }$ & $\alpha_{\min }$ & $\alpha_{\max }$ & $\alpha_{\min }$ & $\alpha_{\max }$ \\
\hline Membrane D & 0.73 & 0.89 & - & - & 0.53 & 0.7 & - & - \\
Membrane E & 0.15 & 0.25 & - & - & 0 & 0.01 & - & - \\
Membrane F & 0.27 & 0.46 & 0.42 & 0.52 & 0.07 & 0.13 & 0.18 & 0.33
\end{tabular}




\section{Figure Captions}

Fig.1. Schematic diagram of the membrane system used.

Fig.2. Variation of the initial hydraulic permeability $L p_{0}$ measured before each successive experiment. Results obtained on six membrane samples A to F.

Fig.3. Theoretical variation of the observed retention $\left(R_{o b s}\right)$ and the intrinsic retention $\left(R_{\text {int }}\right)$ versus permeation flux $J_{v}$.

Fig.4. Use of the "Velocity Variation Method" to determine the intrinsic retention $R_{\text {int }}$. Example of its application with the retention results obtained with a $0.25 \mathrm{M}$ sodium lactate solution on membrane sample A.

Fig.5. Variation of the observed retentions $R_{o b s}$ and of the calculated intrinsic retention $R_{\text {int }}$ with permeation flux $J_{v}$ - Membrane sample A - 0.25 M sodium lactate solution.

Fig.6. Intrinsic retention versus permeation flux for a single-solute solution of glucose $(0.1$ M). Dashed lines : best-fit curves obtained from the linearized transport model [22].

Fig.7 Intrinsic retention versus permeation flux for a single-solute solution of $\mathrm{NaLac}(0.5 \mathrm{M})$. Dashed lines : best-fit curves obtained from the linearized transport model.

Fig.8. Intrinsic retention versus permeation flux for single-solute solutions of glucose Membrane sample D. Influence of glucose concentration. 
Fig.9. Intrinsic retention versus permeation flux for single-solute solutions of sodium lactate Membrane sample D. Influence of NaLac concentration.

Fig.10. Sodium lactate intrinsic retention versus permeation flux for mixed-solute solutions 0.5 M sodium lactate and $0.1 \mathrm{M}$ glucose. Comparison with NaLac retention in single-solute solution.

Fig.11. Glucose intrinsic retention versus permeation flux for mixed-solute solutions $-0.5 \mathrm{M}$ sodium lactate and $0.1 \mathrm{M}$ glucose. Comparison with glucose retention in single-solute solution.

Fig.12. Glucose intrinsic retention versus permeation flux for mixed-solute solutions $-0.5 \mathrm{M}$ sodium chloride and $0.1 \mathrm{M}$ glucose. Comparison with glucose retention in single-solute solution.

Fig.13. Glucose intrinsic retention versus permeation flux for mixed-solute solutions of 0.1 glucose and sodium lactate at two concentrations $(0.5 \mathrm{M}$ and $1 \mathrm{M})$. Comparison with glucose retention in single-solute solution - Membrane sample F.

Fig.14. Glucose intrinsic retention versus permeation flux for mixed-solute solutions of 0.1 glucose and sodium chloride at two concentrations $(0.5 \mathrm{M}$ and $1 \mathrm{M})$. Comparison with glucose retention in single-solute solution - Membrane sample F. 


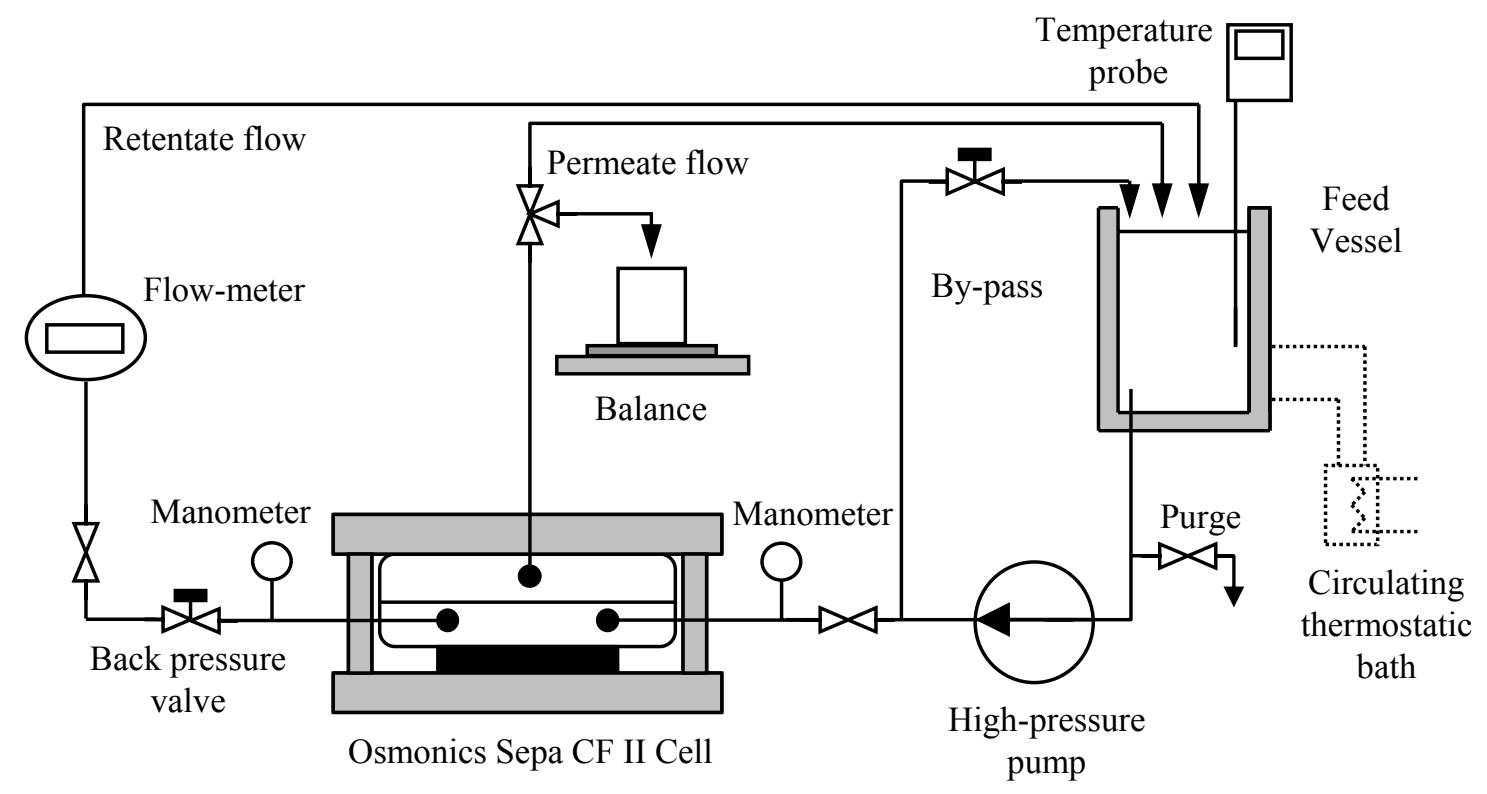

Figure 1 


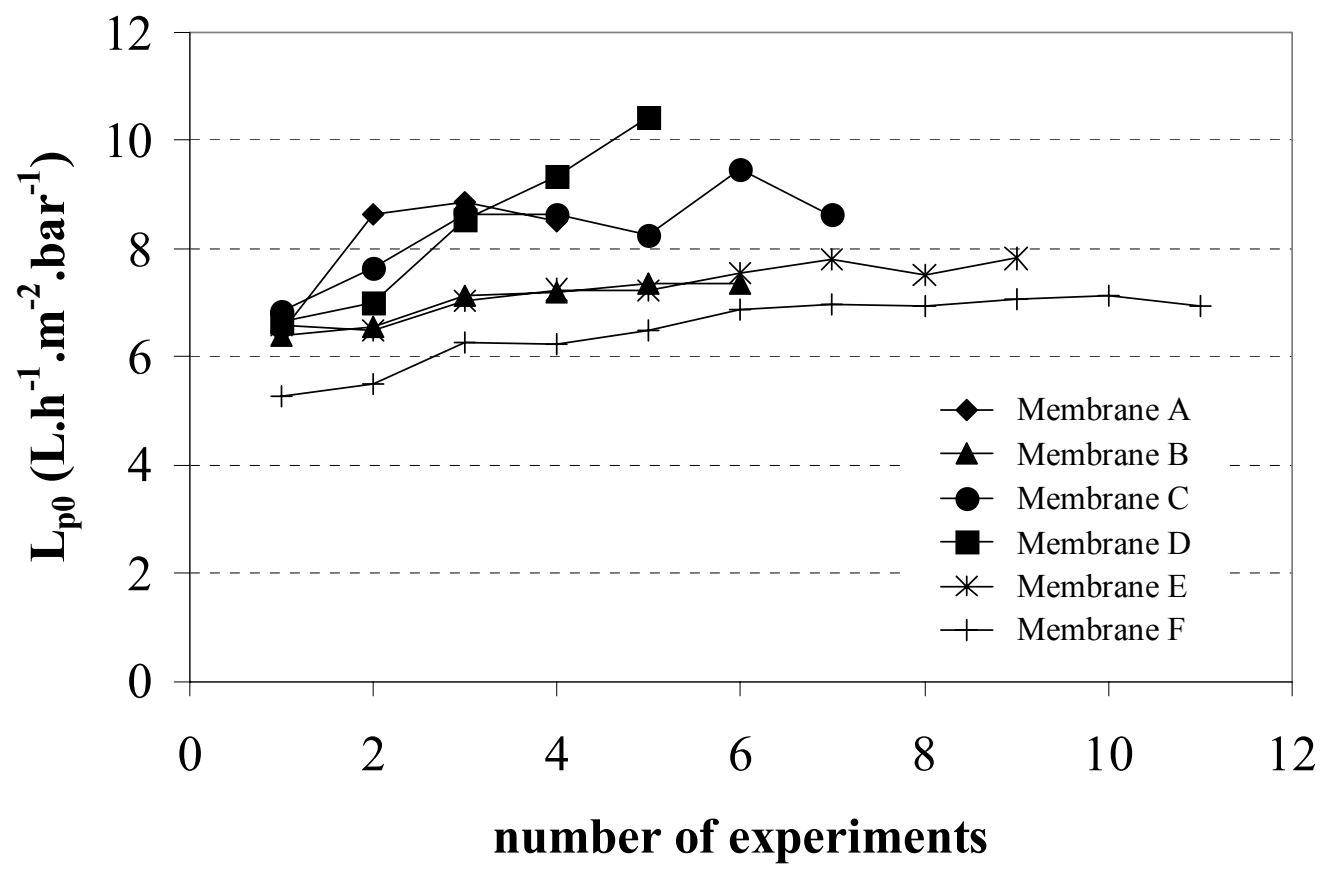

Figure 2 


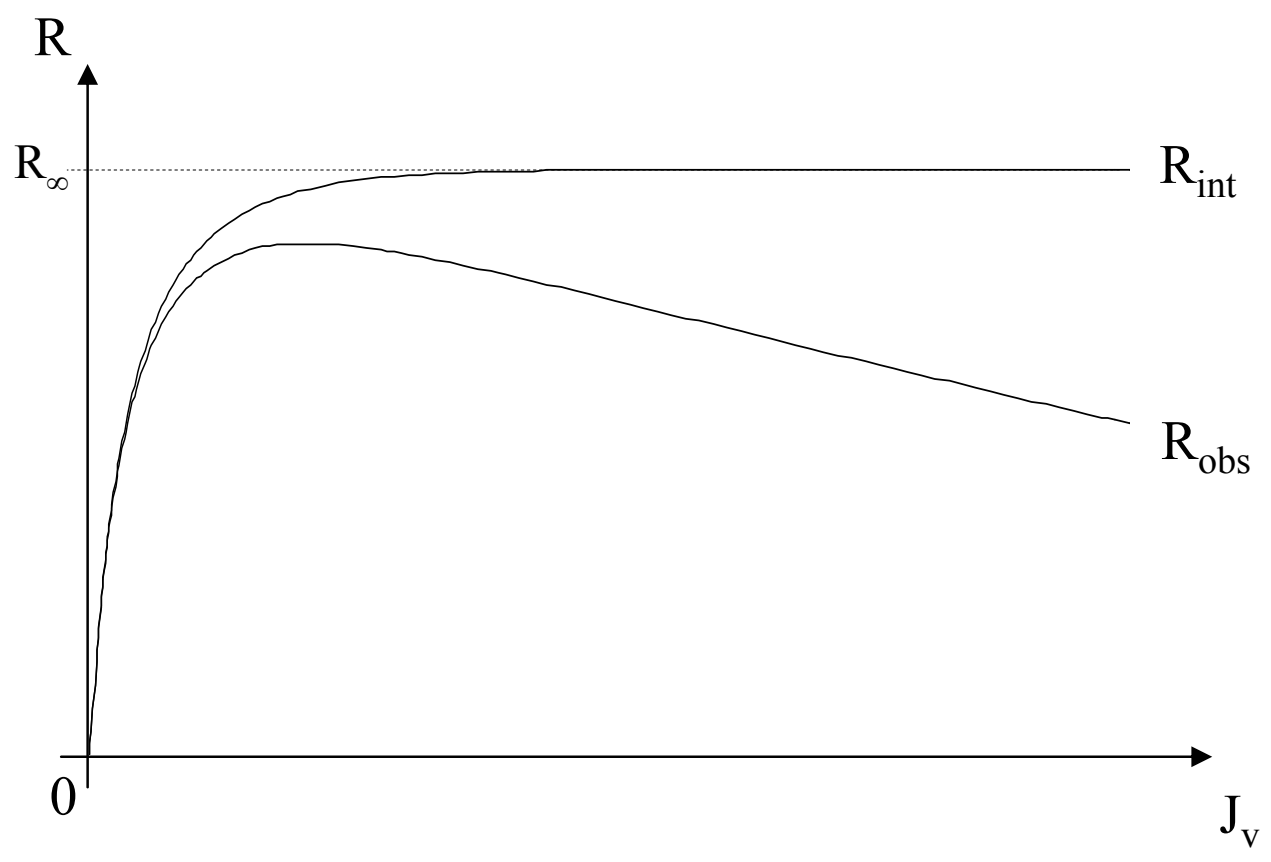

Figure 3 


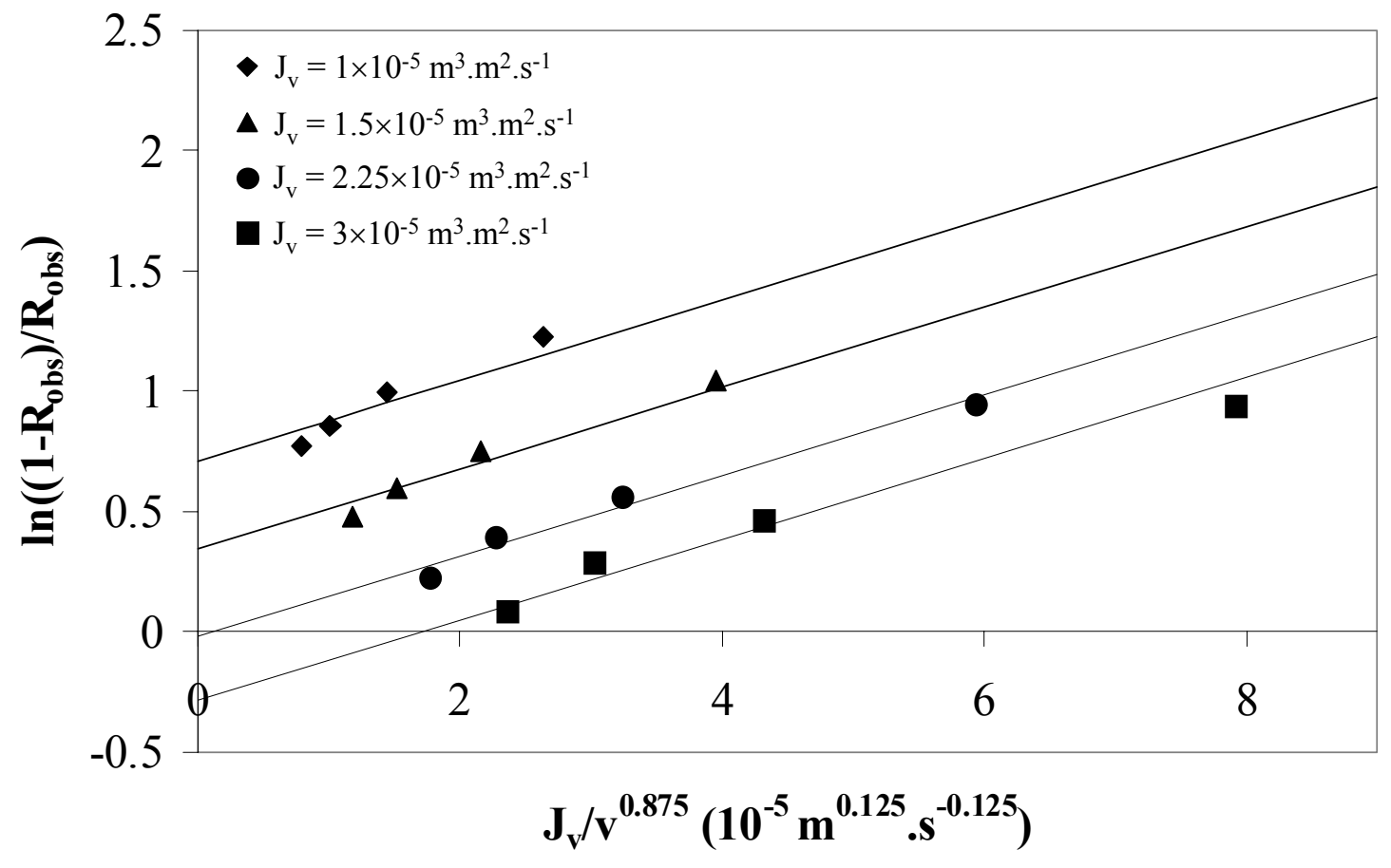

Figure 4 


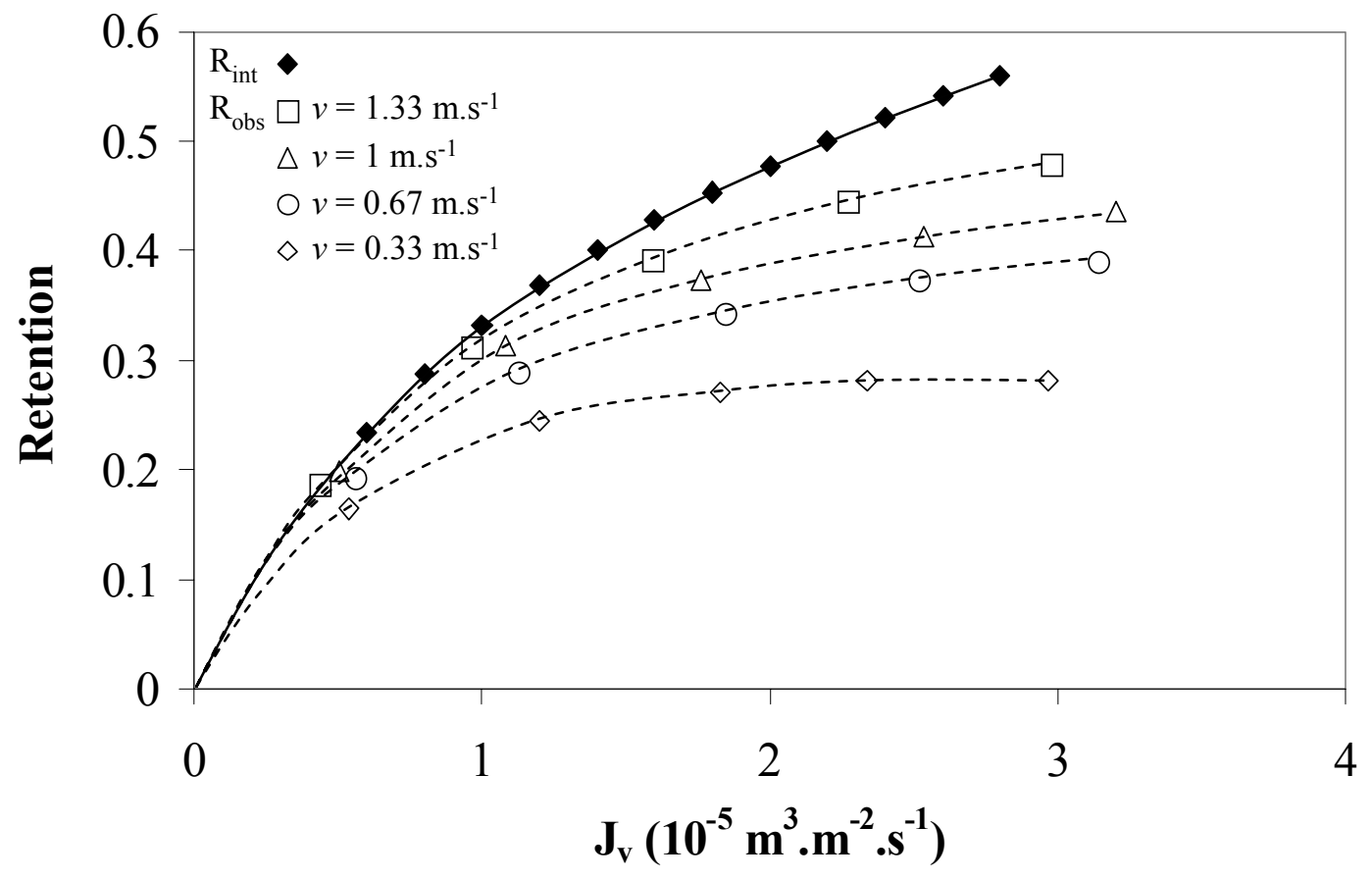

Figure 5 


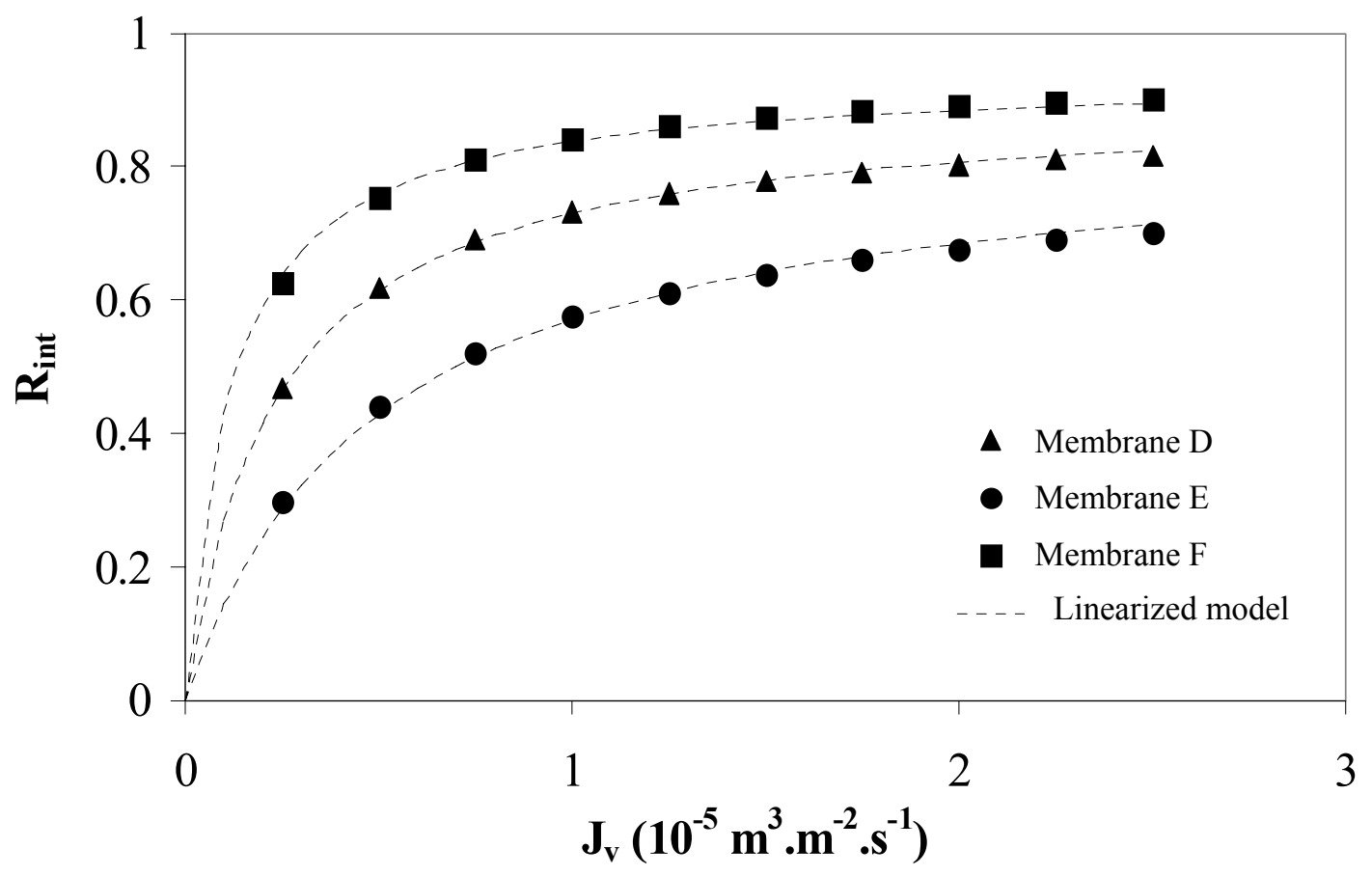

Figure 6 


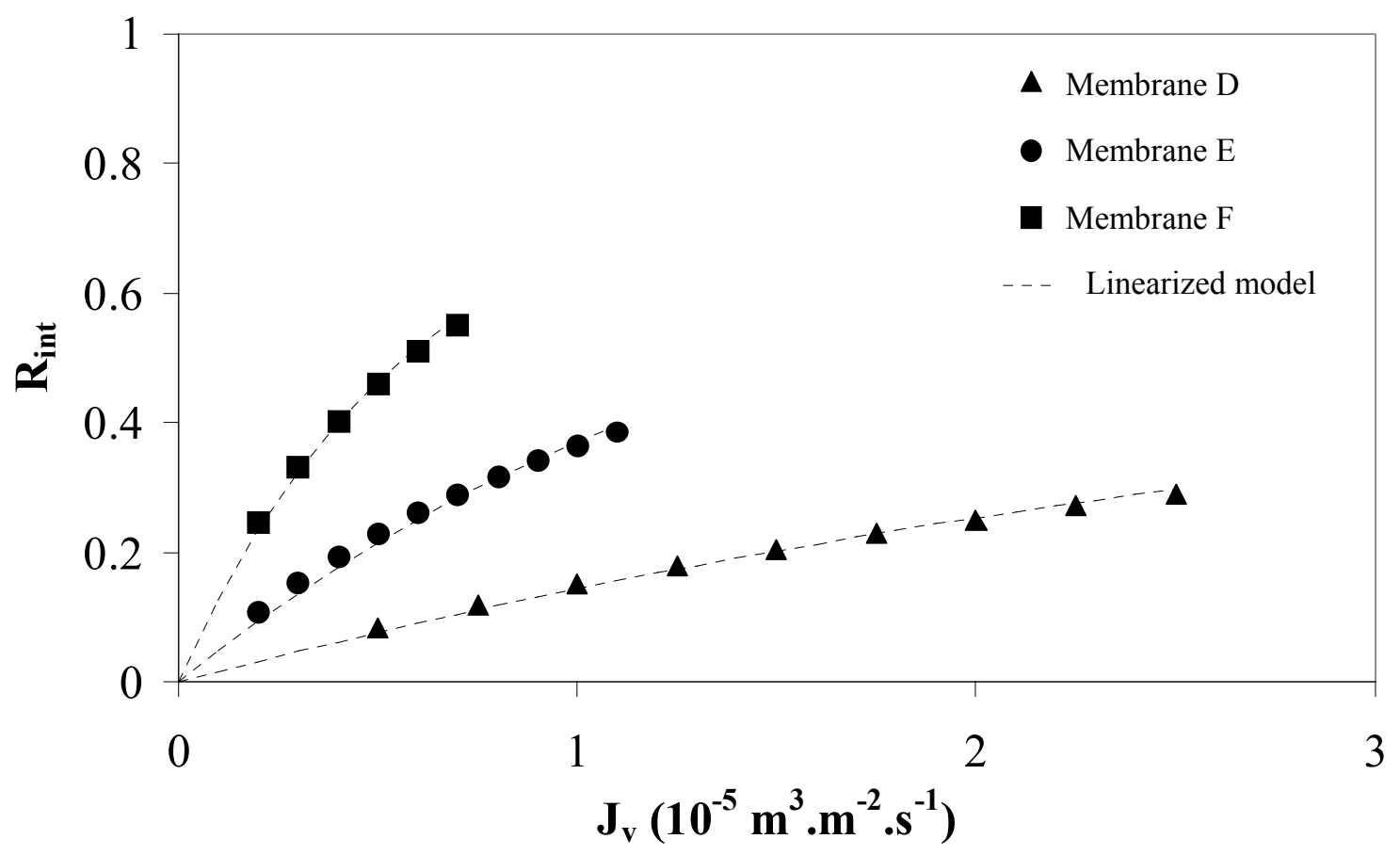

Figure 7 


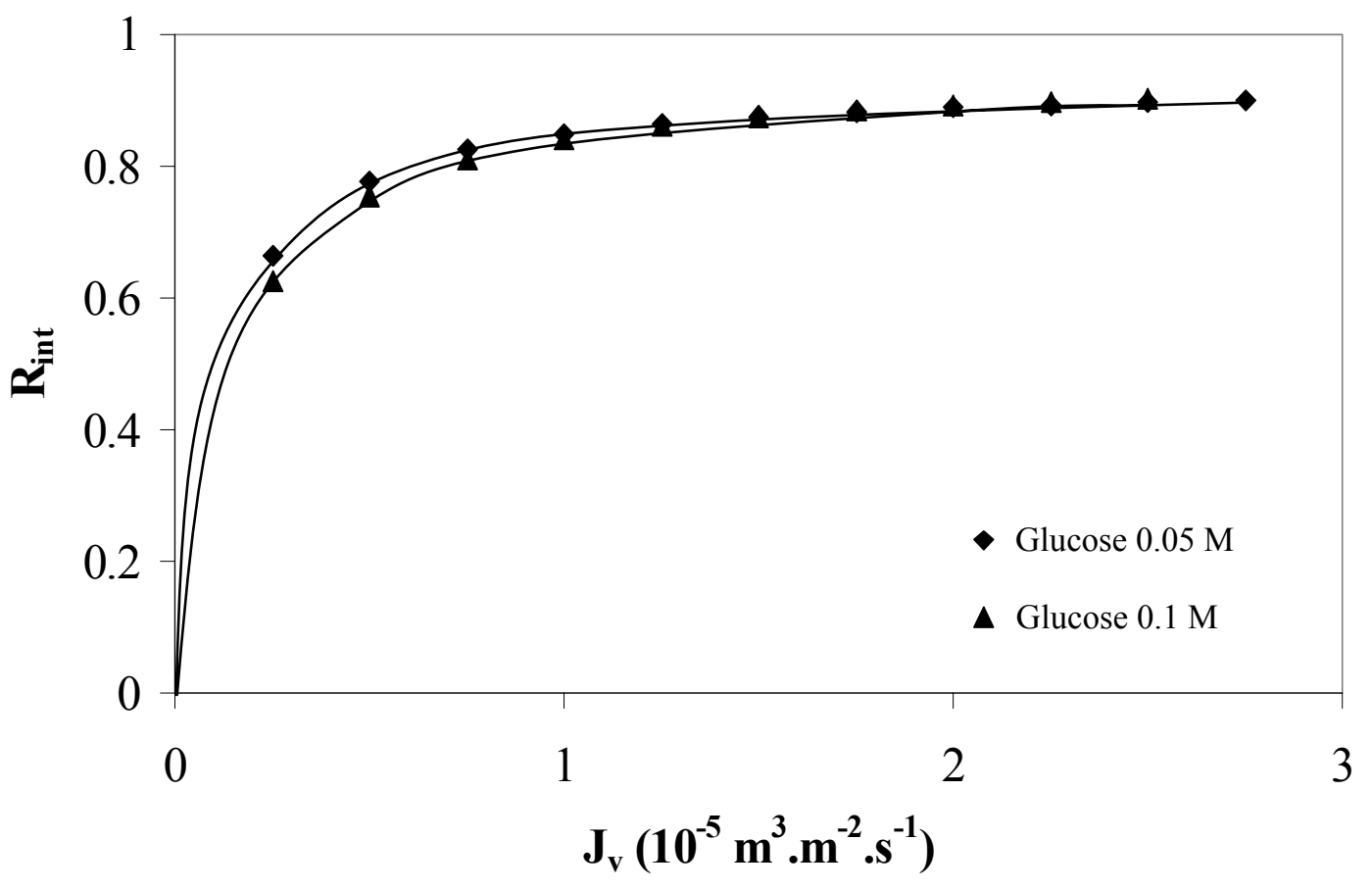

Figure 8 


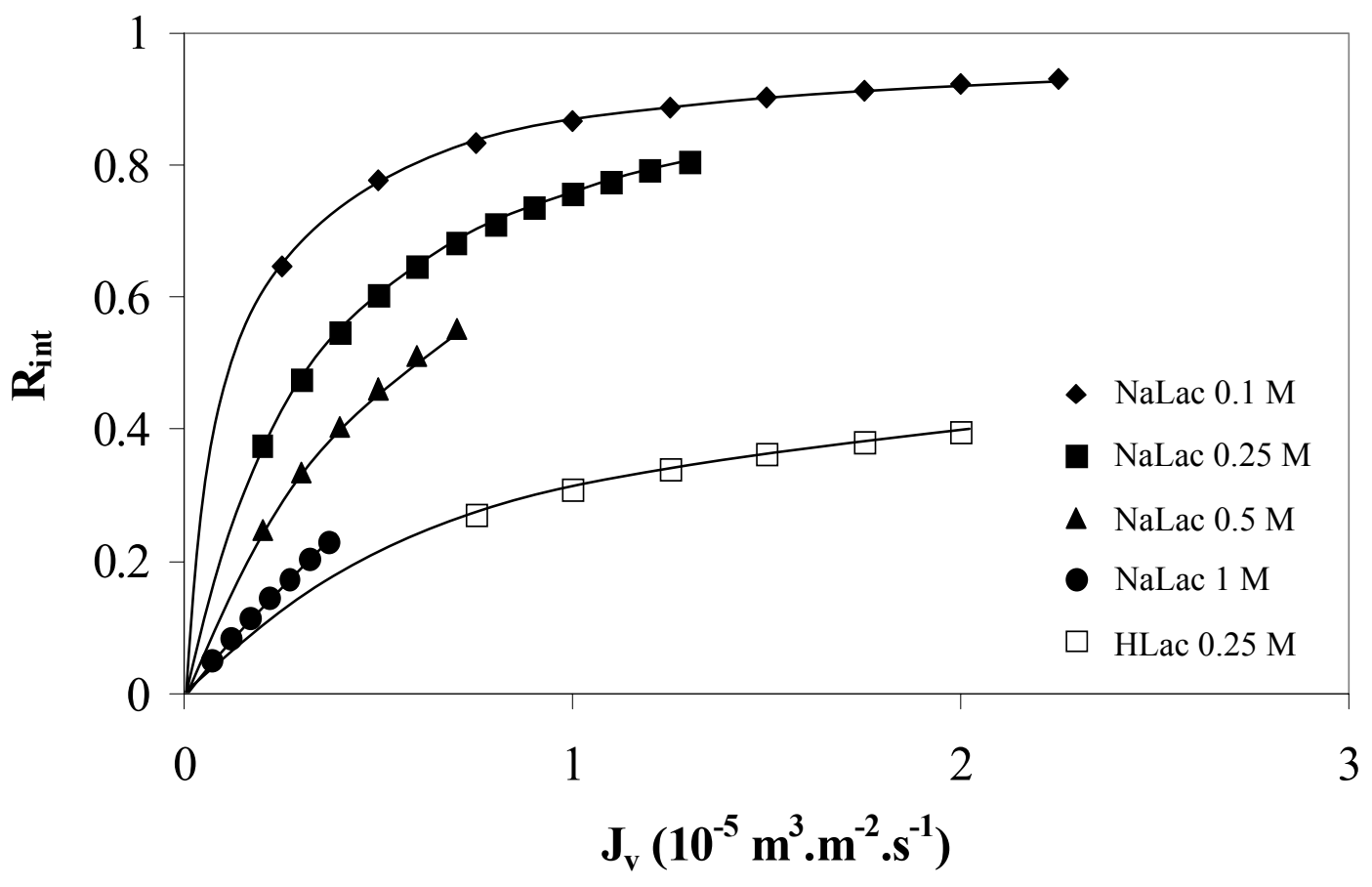

Figure 9 


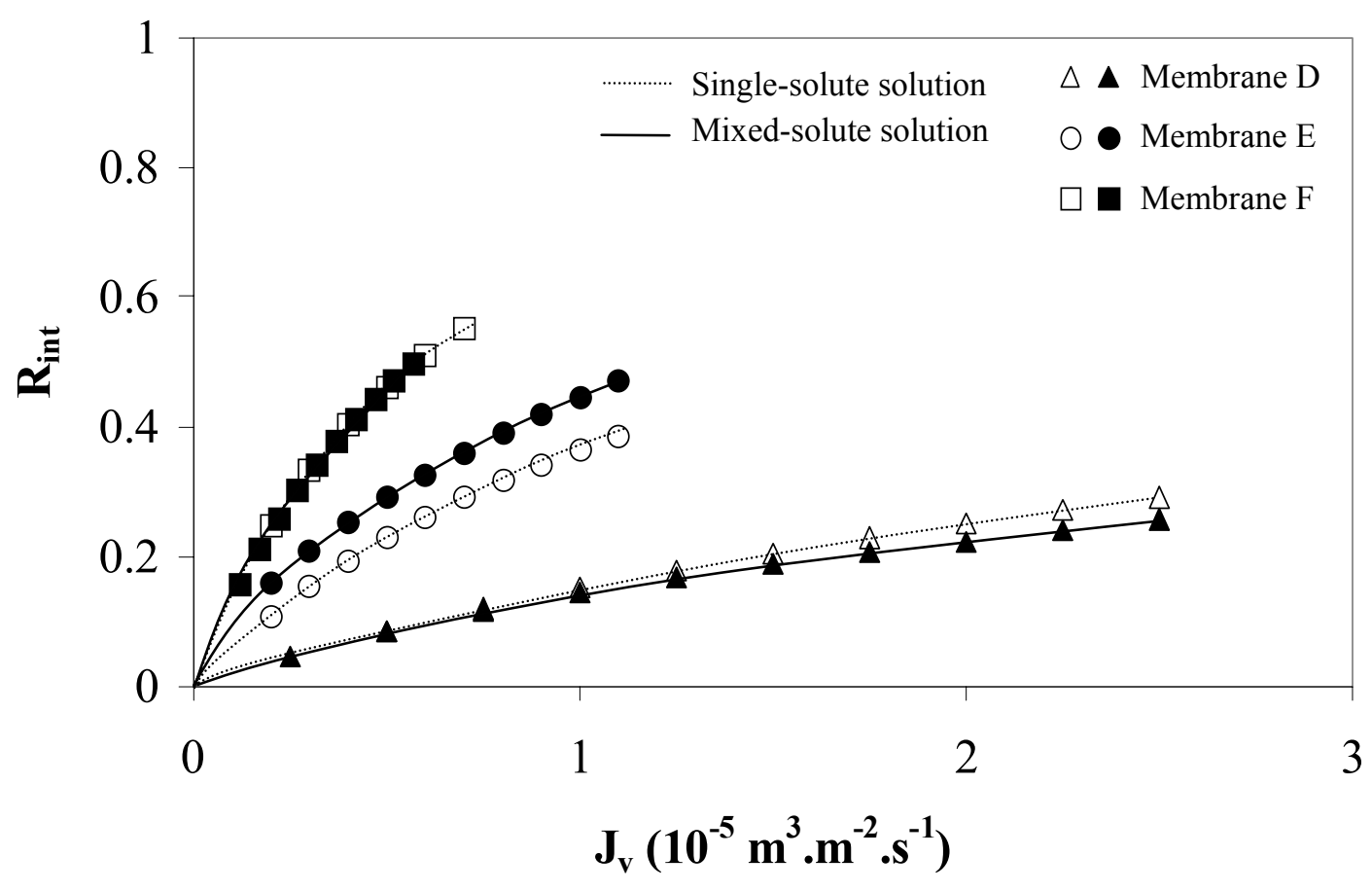

Figure 10 


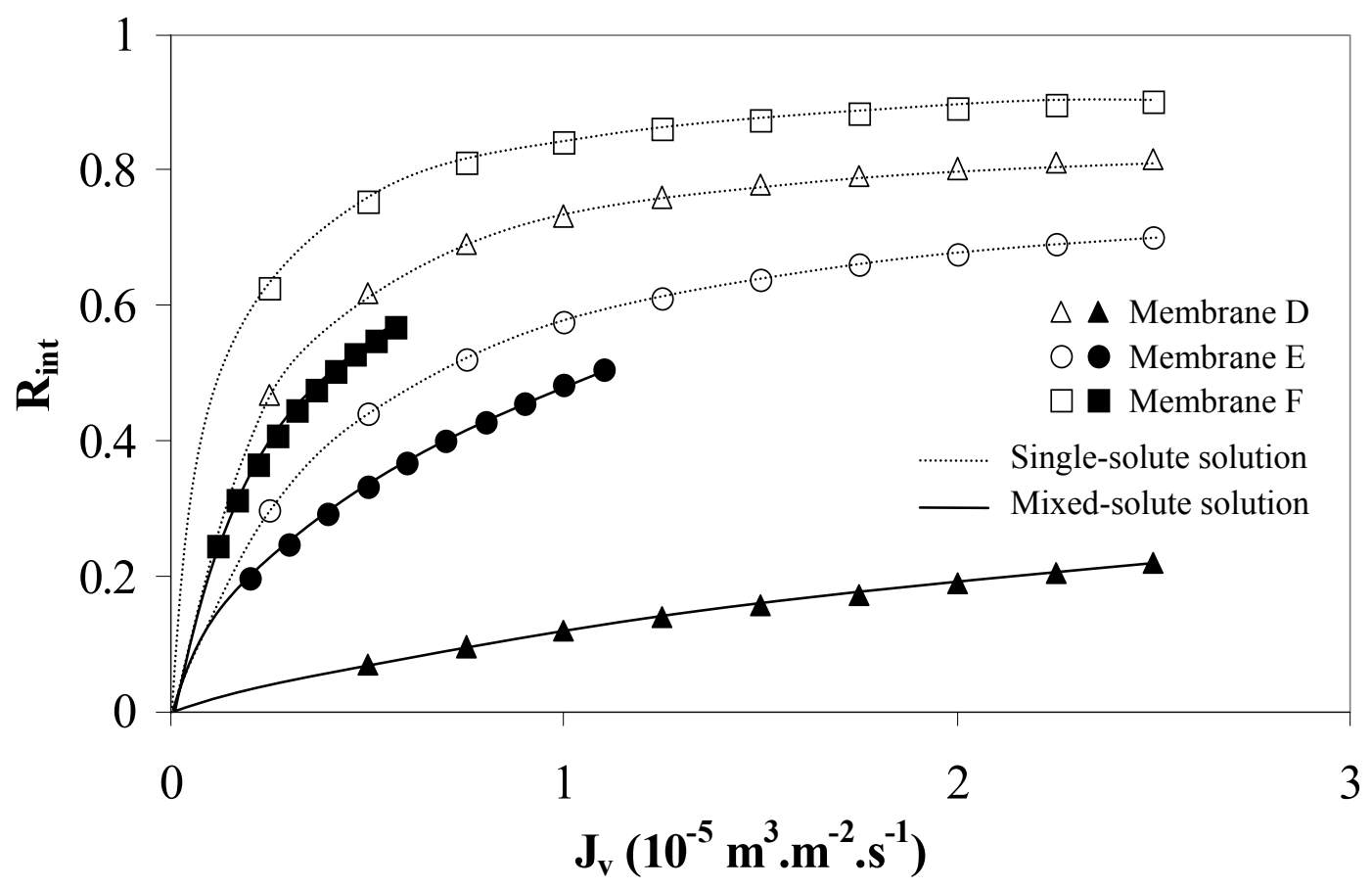

Figure 11 


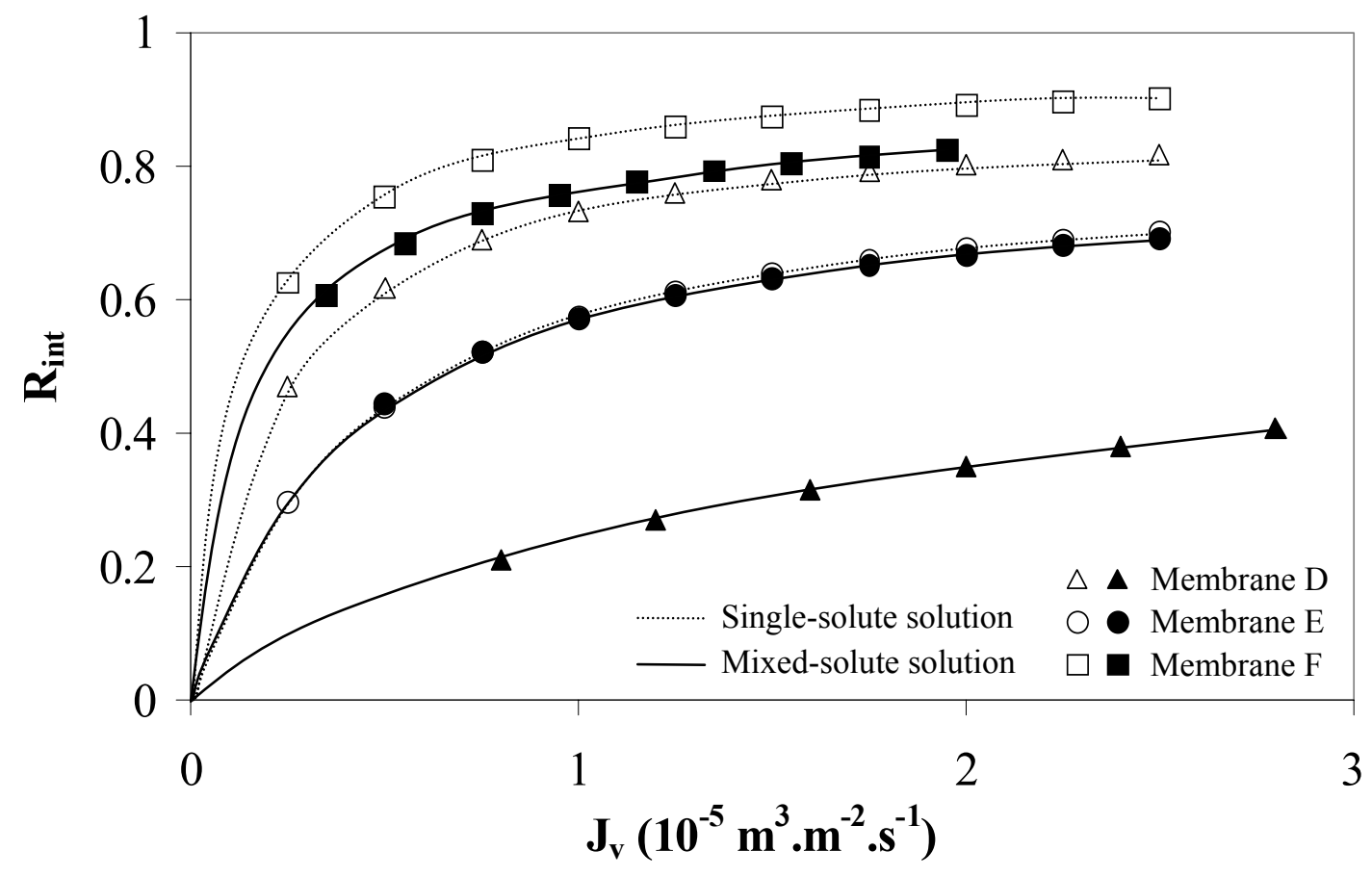

Figure 12 


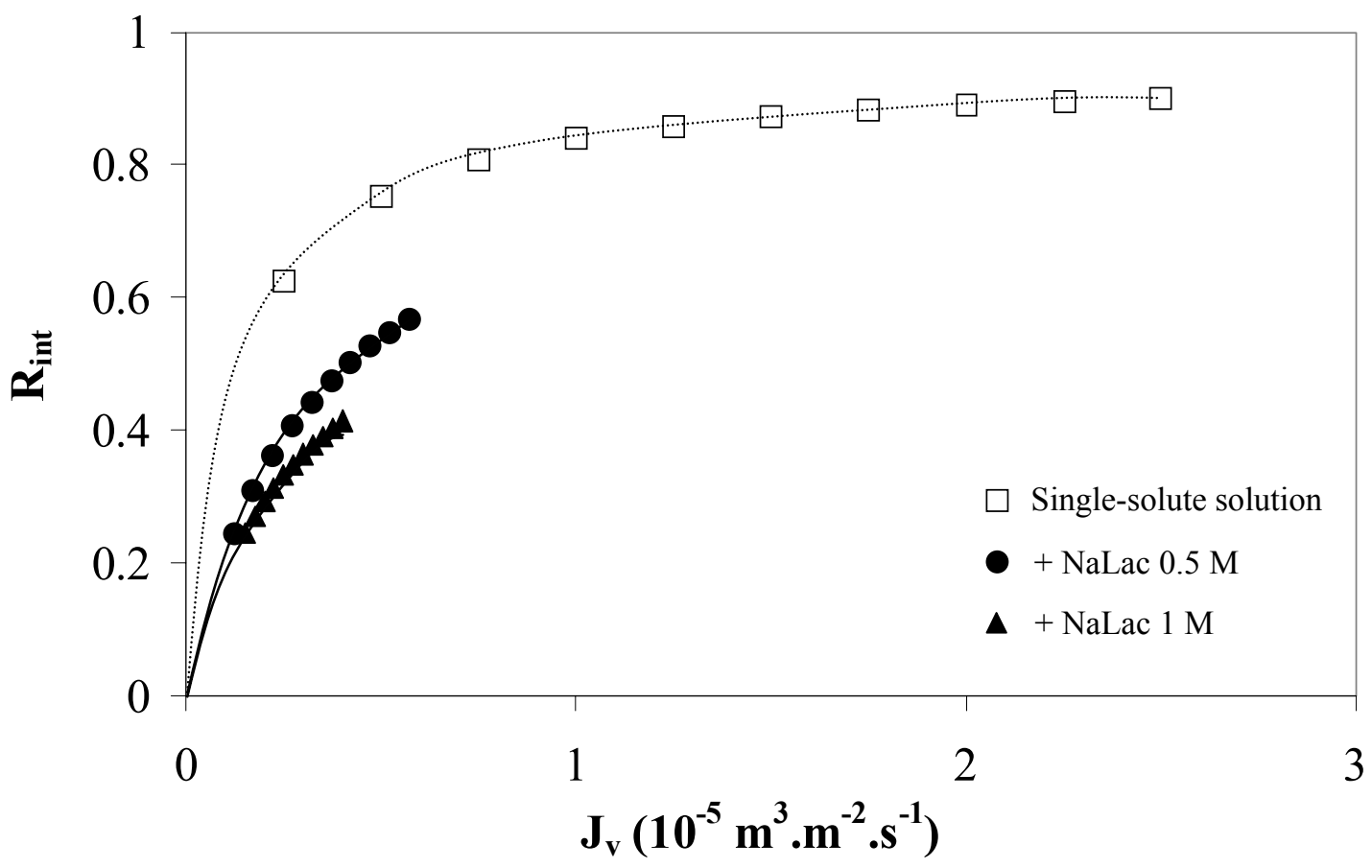

Figure 13 


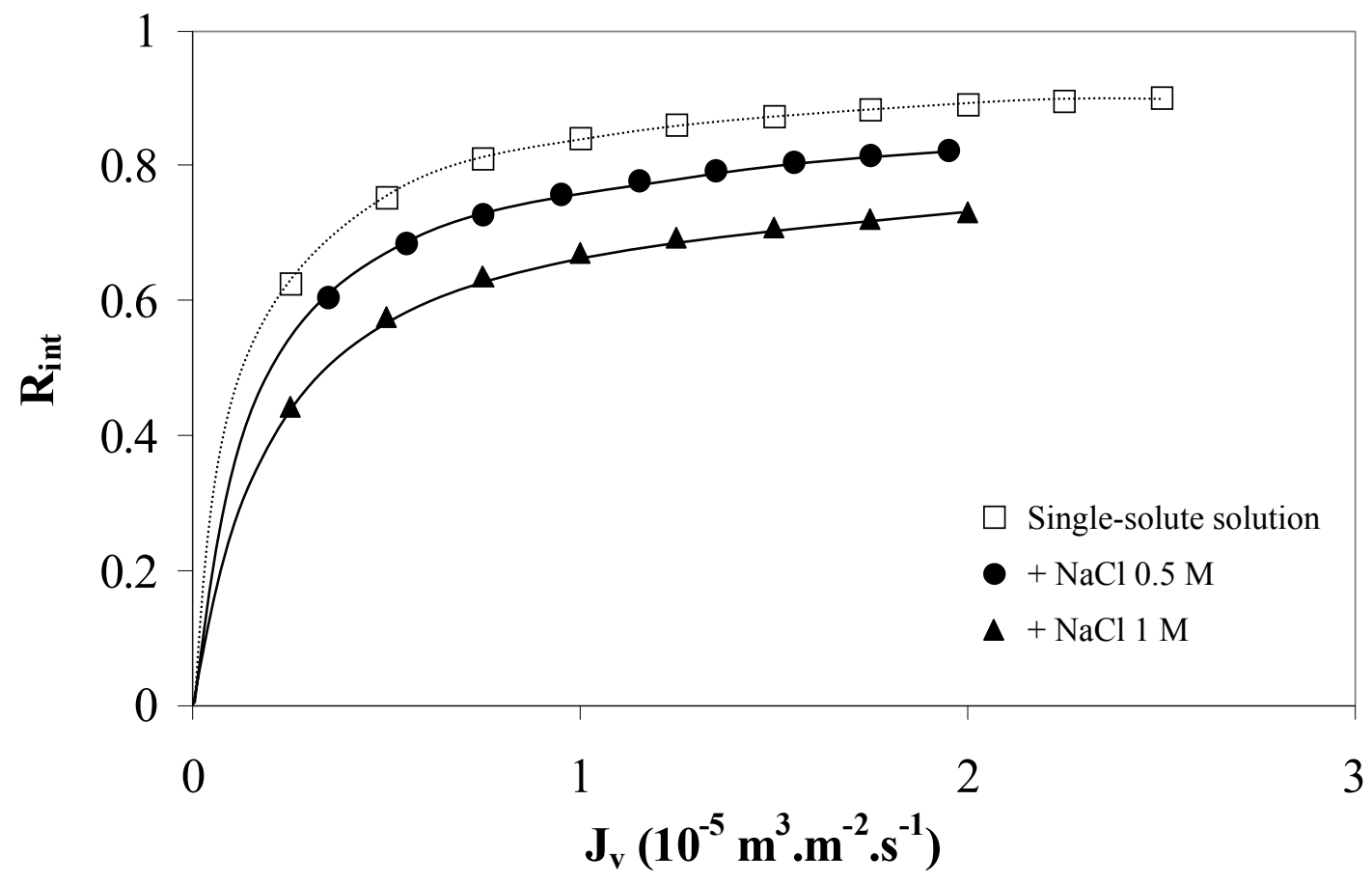

Figure 14 